\title{
Children's disclosures of sexual abuse in a population-based sample
}

\author{
Lahtinen, Hanna-Mari
}

2018-02

Lahtinen , H-M , Laitila , A , Korkman , J \& Ellonen , N 2018, ' Children's disclosures of

sexual abuse in a population-based sample ' , Child Abuse and Neglect , vol. 76 , pp. 84-94 . https://doi.org/10.1016

http://hdl.handle.net/10138/300574

https://doi.org/10.1016/j.chiabu.2017.10.011

publishedVersion

Downloaded from Helda, University of Helsinki institutional repository.

This is an electronic reprint of the original article.

This reprint may differ from the original in pagination and typographic detail.

Please cite the original version. 
Research article

\title{
Children's disclosures of sexual abuse in a population-based sample
}

\author{
Hanna-Mari Lahtinen ${ }^{\mathrm{a}, *}$, Aarno Laitila ${ }^{\mathrm{b}}$, Julia Korkman ${ }^{\mathrm{c}}$, Noora Ellonen ${ }^{\mathrm{d}}$ \\ a University of Eastern Finland, School of Educational Sciences and Psychology, P.O. Box 111, 80101 Joensuu, Finland

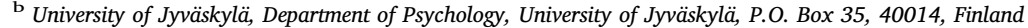 \\ c Psychology at Åbo Akademi University, Helsinki University Hospital, Forensic Psychology Center for Children and Adolescents, 20500 Turku, Finland \\ d University of Tampere, School of Social Science and Humanities, 33014, Finland
}

\section{A R T I C L E I N F O}

\section{Keywords:}

Child sexual abuse

Disclosure

Non-disclosure

\begin{abstract}
A B S T R A C T
Most previous studies on disclosing child sexual abuse (CSA) have either been retrospective or focused on children who already have disclosed. The present study aimed to explore the overall CSA disclosure rate and factors associated with disclosing to adults in a large population-based sample. A representative sample of 11,364 sixth and ninth graders participated in the Finnish Child Victim Survey concerning experiences of violence, including CSA. CSA was defined as having sexual experiences with a person at least five years older at the time of the experience. Within this sample, the CSA prevalence was $2.4 \%$. Children reporting CSA experiences also answered questions regarding disclosure, the disclosure recipient, and potential reasons for not disclosing. The results indicate that most of the children (80\%) had disclosed to someone, usually a friend (48\%). However, only $26 \%$ had disclosed to adults, and even fewer had reported their experiences to authorities (12\%). The most common reason for non-disclosing was that the experience was not considered serious enough for reporting (41\%), and half of the children having CSA experiences did not self-label their experiences as sexual abuse. Relatively few children reported lacking the courage to disclose (14\%). Logistic regression analyses showed that the perpetrator's age, the age of the victim at the time of abuse, and having no experiences of emotional abuse by the mother were associated with disclosing to an adult. The results contribute to understanding the factors underlying children's disclosure patterns in a population-based sample and highlight the need for age-appropriate safety education for children and adolescents.
\end{abstract}

\section{Introduction}

A child's disclosure is often the prime evidence in cases of child sexual abuse (CSA). It is also crucial for ending the abuse, getting help for the child, and preventing other children from becoming victims (Bottoms, Peter-Hagene, Epstein, Wiley, Reynolds, \& Rudnicki, 2016; Pipe et al., 2007a). Given the importance of disclosure, it is not surprising that there has been extensive research related to the subject in recent decades (Malloy, Brubacher, \& Lamb, 2011). Consensus has been largely achieved, for example, on guidelines for interviewing children when abuse is suspected. However, disclosure rates in CSA cases and possible disclosure patterns have been the subject of considerable debate. Some researchers (Pipe, Orbach, Lamb, \& Cederborg, 2007) have

\footnotetext{
Research funding for this paper came from the Academy of Finland (Graduate School for Family Studies), University of Eastern Finland.

* Corresponding author.

E-mail addresses: hanna.lahtinen@uef.fi, hannalah@uef.fi (H.-M. Lahtinen), aarno.a.laitila@jyu.fi (A. Laitila), jkorkman@abo.fi (J. Korkman), noora.ellonen@uta.fi (N. Ellonen).
} 
even referred to the debate as "the disclosure wars". The origin of the war lies in the contradictory findings: disclosure rates vary as much as between $24 \%$ and $96 \%$ (London, Bruck, Wright, \& Ceci, 2008). This is a reflection of the many problems involved in studying the question. One explanation for the contradictory results is the varying sources of information used in different studies (London et al., 2008). The two main sources of information used in the research literature are retrospective surveys of adults reporting CSA experiences and children undergoing forensic evaluations of suspected CSA (London et al., 2008; Olafson \& Lederman, 2006).

Another problem in comparing research results has been the variation in the definitions of both CSA and disclosure. CSA definitions have differed in the types and extent of behaviors included (Bottoms et al., 2016; London et al., 2007; Olafson \& Lederman, 2006). For example, some studies have included unwanted sexual experiences with peers (e.g., Priebe \& Svedin, 2008; Kogan, 2004), whereas others have excluded them (e.g., Lam, 2014; Helweg-Larsen \& Larsen, 2006). Similarly, the definitions of disclosure have varied and have often been expressed implicitly in the research literature. The greatest differences in definitions of disclosure are between surveys and studies of child forensic interviews. In the latter, children are asked to tell about their experiences, and disclosure is referred to as telling about the experience in the interview situation. It is probable that a large number of children in such settings have in fact already revealed their experiences to someone (London et al., 2007; Hershkowitz et al., 2005). In contrast, in population-based surveys, whether the participants were ever asked about CSA prior to the survey is usually unknown. Also, some studies have differentiated between delayed disclosure and non-disclosure, whereas others have not (Pipe et al., 2007b; London et al., 2008).

\subsection{Retrospective surveys}

CSA disclosure rates in retrospective surveys have been quite congruent, varying mostly between $31 \%$ and $45 \%$ (London et al., 2008). Nevertheless, two exceptions report markedly higher disclosure rates. Both of these studies had representative samples of young adults (18-year-olds), whereas the mean age in most of the study samples in the London et al. (2008) review was over 30 years. Priebe and Svedin (2008), for example, reported a disclosure rate of $81 \%$ for girls and $69 \%$ for boys in a Swedish sample. Furthermore, in an earlier study by Fergusson, Lynskey, and Horwood (1996) in New Zealand, the disclosure rate for both boys and girls before the age of 18 years was $87 \%$. Priebe and Svedin (2008) also examined disclosure patterns and concluded that the patterns were different for boys and girls. Attending a vocational educational program and living with both parents predicted non-disclosure among boys, whereas for girls, non-disclosure was predicted by a single occasion of abuse, contact abuse, and a familiar perpetrator (a family member, relative, friend, or acquaintance). For both genders, parental bonding was a significant factor related to disclosure. Children who perceived their parents as caring but not overprotective when growing up were more likely to disclose (Priebe \& Svedin, 2008). Furthermore, earlier retrospective studies of adults with self-reported CSA histories have found that children are often deterred from disclosing for fear of the possible negative consequences. In these adult samples, participants have described that as children they were afraid of revenge or of being punished or blamed for what had happened (e.g., Anderson, Martin, Mullen, Romans, \& Herbison, 1993; Browne \& Finkelhor, 1986; Conte \& Berliner, 1988; Herman \& Hirschman, 1981; Palmer et al., 1999; Wyatt \& Newcomb, 1990). A recent pilot study by Tashjian, Goldfarb, Goodman, Quas, and Edelstein (2016) showed that having also experienced emotional or physical abuse by a parental figure may delay the disclosure.

Although retrospective studies provide a population-based estimate of disclosure rates and factors related to disclosure, there are considerable methodological problems with the retrospective approach to CSA disclosures. First, problems related to memory bias are inevitable. It is possible, for example, that an adult may not recall having disclosed to someone as a child or fail to correctly recall when the disclosure happened. Adults may also have forgotten abusive experiences or, on the other hand, formed false memories of abuse; or they may falsely deny that abuse ever happened (London et al., 2008). Second, adults may reinterpret both the experiences they had and the reasons they might have had for non-disclosing as a child (Malloy et al., 2011).

\subsection{Children evaluated for sexual abuse}

Compared to retrospective studies of adults reporting CSA experiences, disclosure rates in the studies of children evaluated for suspected sexual abuse in forensic settings vary more: from $24 \%$ to $96 \%$. Several possible factors, such as the age of the children interviewed, may account for the large variation. The lowest disclosure rates are found in samples that include greater proportions of young children (younger than 8 years old), boys, intra-familial abuse, or particular ethnic groups (London et al., 2008). An important source of variation in disclosure rates among children undergoing forensic evaluations is the strategy chosen for distinguishing between children who were abused but do not report it and children who were not abused and do not report it (Pipe et al., 2007b; London et al., 2007). Selecting only the cases where external (medical) evidence of abuse was available led Lyon (2007) to conclude that only about half of the sexually abused children disclosed when interviewed. On the other hand, London et al. (2007) analyzed substantiated cases of CSA, where children were formally interviewed, and concluded that children usually (from $76 \%$ to $96 \%$, depending on the sample analyzed) disclosed if properly interviewed. Despite the different approaches, there is agreement that delayed disclosures are not rare and that there are children who do not disclose even when questioned directly about their CSA experiences (Pipe et al., 2007b).

\subsection{Child victim surveys}

Whereas retrospective surveys with adult samples have been carried out in several countries to assess CSA disclosure rates, only a few surveys have explored CSA disclosure within population-based samples of adolescents or children. Kogan (2004) conducted one 
of the first national surveys exploring disclosure rates of unwanted sexual experiences with a representative sample of 12-17-year-old females. The overall disclosure rate in the sample was $74 \%$. The age at the time of the incident was a key factor influencing the decision to disclose and whom to disclose to. Young children under the age of seven were the least likely to tell about unwanted sexual experiences and likewise the most likely to delay disclosure. Kogan (2004) also found that older adolescents (14-17-year-olds) were more likely to tell peers, whereas younger adolescents tended to tell adults about the abuse. Furthermore, a closer relationship to the perpetrator predicted non-disclosure, whereas the severity of abuse (fear for life during the experience, penetration) was related to disclosing to adults.

It is not possible to compare the findings of Kogan (2004) with those of other studies and generalize the results, as only female participants were included in the study. Also, unlike other studies, Kogan's study did not use CSA as a key concept, but examined unwanted sexual experiences more broadly, including peers as perpetrators. However, a Danish national survey (HelwegLarsen \& Larsen, 2006) of 15-16-year-old boys and girls, focusing on unlawful sexual experiences before the age of 15 years, found a disclosure rate of $83 \%$, close to Kogan's finding. Both of the previous studies reported that the experiences were rarely disclosed to the police.

Since the focus of their study was on the prevalence of CSA experiences, Helweg-Larsen \& Larsen (2006) did not analyze the potential disclosure patterns. However, they put forward an important, little-studied perspective by exploring also the adolescent's own perception of the experience and whether this was a factor influencing the decision to disclose. In cases not perceived as sexual abuse, the older person was most often reported as being a friend. There were no statistically significant differences in disclosure rates between the participants who perceived the incident as sexual abuse and those who did not (Helweg-Larsen \& Larsen, 2006). On the other hand, a retrospective study with female college students (excluding the cases where the perpetrator was identified as a romantic partner or a boyfriend) found that victims who labeled themselves as sexual abuse victims were more likely to disclose than victims who did not so label themselves (Bottoms et al., 2016; Bottoms et al., 2007).

Lam (2014) examined predictors of CSA disclosure carefully among 13- to 16-year-olds in two different contexts: clinical and community settings in Hong Kong. Although the generalizability of the results is limited because the sample was a convenience sample and thus not representative, the study yielded some important observations for further research. For example, it showed that associations with disclosure differed depending on the source of information used. Whereas disclosure in the clinical setting was associated with the severity of sexual activities and the adolescent's attachment to their parents, disclosure in the nonclinical setting was influenced by the gender of the abuser and the personality traits of the discloser. Also, disclosers in the clinical sample tended to reveal their CSA experience to adults more often than their counterparts in the community sample. Consistent with the earlier studies (e.g., Priebe \& Svedin, 2008; Kogan, 2004), most of the disclosers (81\%) chose a friend as confidant (disclosure rate 50\%). Lam's (2014) study also showed that adolescents were concerned more about the qualities of their confidants than about the expected responses to the disclosure. They particularly valued a confidant who gave them the feeling of "being listened to patiently" and of "being trusted" (Lam, 2014).

\subsection{The present study}

The findings concerning CSA disclosure have been inconsistent, partly, at least, owing to the methodological issues described above. This argues for the need for further research on the subject (Lyon, 2007; Olafson \& Lederman, 2006; Leclerc \& Wortley, 2015). London and her colleagues (2008, pp. 43) concluded that "Because we cannot do population-based surveys to address this issue (for example asking several thousand children if they were abused in the last year, and if so did they tell anyone, did anyone ask them, and did they deny), we must rely on samples of children questioned about abuse and whose answers have been systematically recorded." However, the present research was designed to tackle the issue of disclosing CSA within a population-based sample of children in the very way suggested to be impossible in the quote above. Population-based research has the advantage of reaching children who have never disclosed to anyone. Compared to retrospective studies, the present study also has the benefit of implying a smaller risk for recall bias as the respondents are still young. Furthermore, adult reinterpretation of the experiences is avoided, since the participants are children (mainly 12-15-year-olds).

The aim of the present study was to contribute to the scientific literature on CSA disclosure by exploring the disclosure rates and factors associated with disclosure in a large population-based sample of children (the Finnish Child Victim Survey). The focus was specifically on factors associated with disclosing CSA to adults (parents and/or authorities), since adults tend to serve as intermediaries regulating the access to getting help and initiating investigation processes (Tashjian et al., 2016). Examining disclosure as a part of the national Victim Survey enabled us to consider also the widely ignored theme of experiencing violence at home and how it might influence disclosing CSA to adults (Tashjian et al., 2016). It was expected that the disclosure rate would be similar to the rates discovered in other representative studies exploring CSA experiences with samples of adolescents or young adults (HelwegLarsen \& Larsen, 2006; Kogan, 2004; Priebe \& Svedin, 2008; Fergusson et al., 1996). Findings in the previous studies have been inconsistent with regard to factors associated with disclosure, and there is a lack of surveys examining children's own reports of reasons for disclosing or non-disclosing (Leclerc \& Wortley, 2015; London et al., 2008; Ullman, 2007). Thus, an exploratory approach was chosen, and no specific research hypotheses were stated. 


\section{Method}

\subsection{Participants}

The data in this study are from the Finnish Child Victim Survey 2013. The nationwide survey has been carried out twice before, in 1988 and 2008. To get a nationally representative sample to participate in the study, a stratified cluster sampling method based on county, type of municipality, and size of the school was used. The final sample consisted of 11,419 sixth and ninth graders from 483 schools in Finland. The response rate was satisfactory, although some of the schools decided not to participate and some did not respond, despite having originally stated that they would do so. The most common reason reported for the schools not to participate was having too few or no computers. Other reasons were lack of time or the fact that they were participating in several other studies already. Taking into account school-level attrition, 75\% of the expected answers were obtained. Fifty-five responses were excluded from the final sample, since they were found to have been sent by teachers or did not treat the matter seriously. The representativeness of the final data was confirmed by comparing the distributions of gender, parental unemployment, parents' education, and family structure to other representative youth surveys in Finland. No systematic differences were found, except that children of highly educated parents were marginally over-represented (Fagerlund, Peltola, Kääriäinen, Ellonen, \& Sariola, 2014).

In the final sample of 11,364 children, there were $55 \%(n=6269)$ sixth graders and $45 \%(n=5095)$ ninth graders. The age of the respondents varied from 10 to 17 years (sixth graders mainly being 12 years old and ninth graders 15 years old in Finland). Respondents' gender distribution was equal.

\subsection{Measures}

The questionnaire used in the 2013 Child Victim Survey was originally constructed for the Child Victim Survey 2008 (Ellonen, Kääriäinen, Salmi, \& Sariola, 2008). The survey covered questions related to different types of victimization, such as violence at home, street violence, cyber victimization, sexual abuse, and reporting of these experiences to authorities, friends, or family members. Most of the questions were based on Finnish modifications of well-known measures such as the Juvenile Victimization Questionnaire (Finkelhor, 2007, 2008; Finkelhor, Ormrod, \& Turner, 2007a,b,c), and the Conflict Tactics Scale (Straus, Hamby, BoneyMcCoy, \& Sugarman, 1994). Questions about sexual experiences were based on a Finnish school survey conducted in 1988 (Sariola \& Uutela, 1992, 1994, 1996) and a Danish school survey conducted in 2002 and 2008 (Helweg-Larsen, 2009). The questionnaire used in the survey in 2008 was pretested with 100 children (Ellonen \& Pösö, 2011b). In order to shorten the questionnaire, in 2013 the further questions concerning sexual experiences focused only on the first experience, rather than three different experiences as in the earlier questionnaires in 1988 and 2008.

The survey, which was web-based, had both multiple-choice questions and open-ended questions. A wide variety of experiences was explored: general criminal violence, sibling and peer victimization, emotional and physical abuse by a parental figure, sexual abuse, violence and harassment connected to online activity and mobile phones, and witnessing domestic violence. Emotional abuse was defined as reporting at least one of the following forms of abuse by a parental figure (separate questions for mother and father): 1) sullenness or refusing to talk, 2) taunting, swearing, or otherwise insulting, 3) throwing, hitting, or kicking an object when angry, 4) threatening with violence (before the child was 14 years old). Physical abuse was assessed by asking if the participants had experienced 1) pushing, shoving, or shaking (with anger), 2) hair pulling, 3) smacking, 4) hitting with the fist, 5) hitting with an object, 6) kicking, 7) spanking, 8) beating, 9) threatening with a knife or a gun, 10) using a knife or gun, or 11) some other violent act by a parent (before the age of 14 years).

The data were collected in August 2013 by the Police University College in Finland. The children had an hour during school hours to complete the survey. Participation in the survey was voluntary, and the anonymity of answers was guaranteed. The survey was administered by teachers who were all accurately instructed beforehand by the research team. The children accessed the questionnaire via a website, which included information about the project and violence in general. The mean time taken to answer the questions was $29 \mathrm{~min}$.

\subsubsection{Definition of CSA and disclosure}

To align the definition of CSA in the present study as closely as possible with the legal definition in the Finnish Penal Code, CSA was defined as having had an experience of a sexual approach by or intercourse with an adult or with someone who was at least five years older at the time of the experience. This is also close to the definition of CSA applied by Helweg-Larsen and Larsen (2006) and similar to that used in the earlier Finnish Child Victim Surveys (Sariola \& Uutela, 1994; Ellonen et al., 2008). In the Finnish Penal Code, CSA is defined as perpetrating any sexual act on a person younger than 16 years of age, or getting her/him to perform such an act, the act being apt to impair her/his development. Additionally, an attempt to carry out such an act is punishable under the Code. In Finland, the minimum age of criminal responsibility is 15 years. The question in the present survey exploring the experiences was: "Do you have experiences of a sexual approach by or intercourse with adults or with someone who was at least five years older than you at the time of the incident?" To discover whether the respondents experienced the events as CSA, they were also asked: "Did you experience the incident as sexual abuse?" (response options: yes, maybe, no, not sure). Although the minimum age of criminal responsibility is 15 years, the five cases in the data in which the perpetrator was under 15 years of age were also included in the analyses. This was because, according to the Finnish Penal Code, the police have an obligation to investigate cases where the perpetrator is under 15 years of age, and the liability for damages for the victim of the crime is considered in all cases. Moreover, it was considered that the experience of the victim is not dependent on the age of the other person involved. 
In cases in which children had several experiences of CSA, they were instructed to think about the first experience when answering the further questions regarding the sexual experience. Children reporting sexual experiences with a person at least five years older were first asked to answer the question: "What happened?" It was possible to choose several of the 10 options: invitation or proposition to do something sexual, petting, the person showed her/his genitals, you showed your genitals to her/him, the person touched your genitals (with clothes in between), you touched her/his genitals (with clothes in between), the person touched your naked genitals, you touched her/his naked genitals, imitating intercourse without penetration, and penetration. All the options were considered as different forms of CSA in the present study. The "invitation or proposition to do something sexual" was included, since, according to the Finnish Penal Code, it is in certain circumstances considered as CSA or attempted CSA, rather than grooming (see for example Tolvanen \& Fors, 2013).

Similarly to most of the survey studies (e.g., Priebe \& Svedin, 2008; Helweg-Larsen \& Larsen, 2006; Fergusson et al., 1996; Lam, 2014; London et al., 2008 review) on CSA experiences and disclosure, disclosure in the present study refers to telling someone about the CSA experience before completing the survey. It was measured by asking: "Did you ever tell anyone about the first sexual experience you had with a person at least five years older than you? You can choose any one or more of the following options, if they apply." The options were: mother, father, sister or brother, friend, teacher, police, school nurse, school counselor, social worker, nobody, someone else (specify who). The children who chose the option "nobody" were considered non-disclosers. Excluded from the assessment were possible delays in disclosure and whether anyone had ever asked about the CSA experience.

In addition to the questions about having sexual experiences with a person at least five years older, children were asked to evaluate the experience: was it, with hindsight, very positive, quite positive, insignificant, quite negative, or very negative? The survey also included questions concerning the relationship with the perpetrator, frequency of the experience, victim and perpetrator age at the time of the incident, possible use of force, intimidation, blackmail, violence, bribery, and use of alcohol related to the CSA experience. The non-disclosing children were also asked to select possible reasons for the non-disclosure from six different options ("I did not think it was so serious," "I did not have the courage to tell," "I did not believe that anyone would be interested," "I did not believe that disclosing would help me," "I was too ashamed to disclose," and "Some other reason [specify what]". Background variables measured included gender, age, family structure, parents' socio-economic status, and immigrant status (see more details in Fagerlund et al., 2014).

\subsection{Ethical considerations}

The study was conducted according to Finnish research ethics guidelines in social research. Parental consent was not required. The Constitution in Finland favors hearing children, and parental approval for children's participation is therefore required only in medical research. Finland is also committed to following the United Nations Convention on the Rights of the Child, one of the core principles of which is the right to participate. Moreover, the Ombudsman for Children in Finland issued a statement (2012) declaring that sixth and ninth graders are competent to decide for themselves whether to participate in the study or not. Therefore, parents were not informed about the study until it was already completed, with one exception: Helsinki, the capital city. Helsinki required that parents have the option of prohibiting their children from participating in the study. For more detailed consideration of ethical issues related to conducting the Finnish Child Victim Survey, see Ellonen and Pösö (2011a,b).

\subsection{Statistical analyses}

The analyses in this study focus on the subsample of 256 children and adolescents who reported having sexual experiences with adults or with someone at least five years older at the time of the incident. First, a series of chi-square tests was performed to examine potential variables associated with disclosure at a general level (disclosing at least to someone). No statistically significant relationships were found between the children's individual characteristics and disclosure or between the characteristics of the abuse and disclosure (possibly owing to the small group of non-disclosers, $n=51$ ). Next, a series of chi-square tests was performed to investigate variables potentially associated with disclosure to at least one adult (mother, father, teacher, police, school nurse, school counselor, and/or social worker), compared to non-disclosing or disclosing only to peers. Logistic regression analyses were performed to examine which of the variables predicted disclosing CSA to adults when the influence of other variables was controlled. All data were analyzed with SPSS for Windows version 21.

\section{Results}

\subsection{CSA prevalence and characteristics}

Of the total sample of 11,364 children, $2.4 \%(n=256)$ reported having had sexual experiences with someone at least five years older. Of these, $45 \%$ reported having had a single experience, and $20 \%$ reported it happened from two to 10 times; $13 \%$ had had more than 10 CSA experiences (missing data: $22 \%, \mathrm{n}=55$ ). Most of the children who reported CSA experiences were ninth graders $(87 \%)$ and girls (79\%). The median age of the victim at the time of the experience was 14 years, of the perpetrator 23 years. Most of the perpetrators $(64 \%)$ were at least 20 years of age. The median for the age difference between the child and the perpetrator was nine years $(M=18.37$, S.D. $=1.25)$. The age of the perpetrator was missing in $20 \%(n=51)$ of the responses. Forty-six percent $(n=119)$ of the children reporting CSA experiences also had experienced emotional abuse by their mother and $38 \%(n=97)$ by their father. Physical abuse by the mother was reported by $20 \%(n=52)$ of the children, and $16 \%(n=41)$ reported physical abuse 
Table 1

Number and distribution of types of sexual experiences for both genders $(n=256)$.

\begin{tabular}{lll}
\hline & Boys (n=41) & Girls (n = 186) \\
\hline Non-contact only & $5(12 \%)$ & $62(33 \%)^{* * *}$ \\
Contact, but no penetration & $12(29 \%)$ & $90(49 \%)^{* * *}$ \\
Penetration & $24(59 \%)$ & $34(18 \%)^{* * *}$ \\
\hline
\end{tabular}

*** $p \ll 0.001$. Missing data $\mathrm{n}=29$ (girls 16, boys 13).

by the father.

Only $16 \%(n=35)$ of the children who reported having sexual experiences with a person at least five years older assessed the experience as constituting sexual abuse. A little over half of the respondents (51\%) had not experienced the incident as sexual abuse. On the other hand, a considerable proportion of the children were not sure or did not know (33\%) how to describe the experience. Sixth graders labeled the experience as sexual abuse or were uncertain how to label it more often than ninth graders $\left(\chi^{2}(1)=3.89\right.$, $p=0.049)$. No statistically significant difference was found between the boys and the girls in self-labeling the experience $\left(\chi^{2}(1)\right.$ $=3.35, p=0.067$ ).

As Table 1 shows, sexual experiences with a person at least five years older mostly included contact (excluding penetration). Twenty-three percent of the children reported experiencing penetration, boys more often than girls $\left(\chi^{2}(1)=18.54, p \ll 0.001\right)$; whereas $29 \%$ of the respondents reported having only non-contact experiences (invitation/proposition to do something sexual or exhibitionism). Boys and girls showed statistically significant differences in evaluating the experience. For the boys, the experience was often positive (71\%), whereas only $26 \%$ of the girls evaluated the experience as positive. Almost half of the girls (46\%) evaluated the experience as negative, compared to $9 \%$ of the boys evaluating the experience as negative $\left(\chi^{2}(2)=27.12, p \ll 0.001\right)$. Of all the children who had sexual experiences with a person at least five years older, $34 \%$ evaluated the experience as positive and $27 \%$ as insignificant, whereas $40 \%$ of the experiences were evaluated as negative. No statistically significant difference in evaluating the experience was found between sixth and ninth graders. Thirteen percent of the respondents reported that the perpetrator used violence, boys $(28 \%)$ more than girls $(9 \%)\left(\chi^{2}(1)=12.07, p \ll 0.01\right)$. Force, intimidation, or blackmail was reported in $20 \%$ of the CSA experiences.

In $35 \%$ of the cases, the perpetrator was unfamiliar to a child; however, $14 \%$ of the children reported the perpetrator as being a friend and $16 \%$ as someone whom they knew, but not a friend, and $8 \%$ identified the perpetrator as a romantic partner. Intra-familial CSA was rather uncommon in the sample: $6 \%(n=15)$ of the children reporting sexual experiences with a person at least five years older $(n=256)$ stated that the other person was father, mother, brother, grandparent, or uncle/aunt $(0.1 \%$ of the total sample of 11,364).

\subsection{Disclosure rate and recipients of disclosure}

Most of the children (80\%) had disclosed CSA to someone. The recipient of the disclosure was mostly a friend (48\%) or a parent (mother $20 \%$, father $12 \%$ ). However, only $12 \%$ had reported the experiences to authorities (teacher (5\%), police (7\%), school nurse (2\%), school counselor (3\%), or social worker (4\%)). Eleven percent of the children reported disclosing the experience to a sibling, and $6 \%$ chose the option "someone else" (for example a boyfriend, a relative, or a pet). The disclosure rate for at least one of the previously mentioned adult recipients was $26 \%$. The most popular reason for not disclosing was considering the experience not serious enough (41\%). The remaining responses were distributed quite evenly between the other options: "I did not have the courage to tell" (14\%), "I did not believe that anyone would be interested" (14\%), "I did not believe that disclosing would help me" (14\%), and "I was too ashamed to disclose" (10\%). Eight percent of the children reported having some other reason not to disclose (such as "I did not want to," "There was nothing to tell," or "I enjoyed it").

\subsection{Children's individual and abuse characteristics related to disclosing CSA to adults}

Analysis of variables associated with disclosure of CSA to at least one adult indicated that several individual and abuse-related variables were significantly related to disclosing. Table 2 presents the results of a series of chi-square tests performed to examine each relationship. The analyses show that self-labeling the experience as sexual abuse or being uncertain how to label the experience was associated with disclosing to an adult, rather than not disclosing or disclosing to peers only. Also, if the experience was evaluated as negative, children were more likely to disclose to adults, compared to experiences evaluated as positive or insignificant. Furthermore, the child's age at the time of the experience was associated with disclosing to an adult. A greater proportion of the children under seven years old at the time of the incident reported disclosure to an adult compared to children aged 12-15 years at the time of the incident. Analyses further showed that experiencing emotional abuse by the mother was related to non-disclosure or disclosing only to peers. No similar associations between emotional abuse by the father and disclosure to an adult or physical abuse by either of the parental figures and disclosure were detected.

The perpetrator's age was the most significant abuse-related variable associated with disclosure to an adult. If the perpetrator was at least 30 years old at the time of the incident, children disclosed to an adult more often compared to younger perpetrator age groups. Since the age of the child and the perpetrator at the time of the incident were correlating $(r=-0.28$, $\mathrm{p} \ll 0.01)$, the age 
Table 2

Individual and abuse characteristics associated with disclosing to adults.

\begin{tabular}{|c|c|c|c|}
\hline & Disclosed to adult $(n=67)$ & Disclosed to peers only/No disclosure $(\mathrm{n}=189)$ & Cramer V \\
\hline \multicolumn{4}{|c|}{ Children's individual characteristics } \\
\hline \multicolumn{4}{|c|}{ Self-labeling the experience as CSA } \\
\hline yes/not sure & $45 \%$ & $55 \% * * *$ & \\
\hline no & $14 \%$ & $86 \%$ & 0.340 \\
\hline \multicolumn{4}{|c|}{ Quality of experience } \\
\hline positive & $16 \%$ & $84 \% * * * *$ & \\
\hline insignificant & $18 \%$ & $82 \%$ & \\
\hline negative & $46 \%$ & $54 \%$ & 0.319 \\
\hline \multicolumn{4}{|c|}{ Child's age (years) } \\
\hline $1-6$ & $77 \%$ & $23 \% * * * *$ & \\
\hline $7-11$ & $49 \%$ & $51 \%$ & \\
\hline $12-15$ & $21 \%$ & $79 \%$ & 0.349 \\
\hline \multicolumn{4}{|c|}{ Experienced emotional abuse by mother } \\
\hline yes & $44 \%$ & $69 \% * *$ & \\
\hline no & $56 \%$ & $31 \%$ & 0.239 \\
\hline \multicolumn{4}{|c|}{ Abuse characteristics } \\
\hline \multicolumn{4}{|c|}{ Perpetrator's age (years) } \\
\hline $11-19$ & $22 \%$ & $78 \% * * * *$ & \\
\hline $20-29$ & $17 \%$ & $83 \%$ & \\
\hline 30 or more & $49 \%$ & $51 \%$ & 0.315 \\
\hline \multicolumn{4}{|c|}{ Age difference (years) } \\
\hline $5-9$ & $15 \%$ & $85 \% * *$ & \\
\hline 10-19 & $35 \%$ & $65 \%$ & \\
\hline 20 or more & $34 \%$ & $66 \%$ & 0.212 \\
\hline \multicolumn{4}{|l|}{ Violence } \\
\hline Yes & $52 \%$ & $48 \% * *$ & \\
\hline No & $26 \%$ & $74 \%$ & 0.185 \\
\hline \multicolumn{4}{|c|}{ Force, intimidation, blackmail } \\
\hline yes & $42 \%$ & $58 \% *$ & \\
\hline no & $26 \%$ & $74 \%$ & 0.136 \\
\hline
\end{tabular}

${ }^{*} p \ll 0.05 * * p \ll 0.01 * * * p \ll 0.001$.

difference between the child and the perpetrator was also examined as a potential factor related to disclosure to an adult. It was found that the greater the age difference between a child and a perpetrator, the greater was the proportion of children reporting disclosure to an adult. Furthermore, two abuse-related variables that measured the severity of the CSA experience were found to be associated with disclosure to an adult, namely the perpetrator's use of violence and use of force, intimidation, or blackmail. However, no statistically significant connections between disclosing to an adult and the other offence-related variables measured (such as experience including penetration, frequency of experience, perpetrator using bribery, or use of alcohol at the time of the incident) were found. Neither were there significant associations between disclosure to an adult and individual background characteristics measured (such as gender, family structure, cultural background, parents' education, or socio-economic status). However, it should be noted that for many of the background factors observed, frequencies were very small. For example, intra-familial CSA was so rarely reported that it was impossible to tell if it was more infrequently disclosed than CSA perpetrated by a non-family member (perpetrator being a parent, step-parent, grandparent, sibling, uncle, or aunt, $n=17$ ).

\subsection{Multivariate prediction of disclosing CSA to an adult}

Exploratory correlations (Spearman's coefficient) were first performed among all disclosure predictors to detect potential multicollinearity. Multicollinearity was not detected between the predicting variables, except in the case of the perpetrator's age and age difference, where Spearman's coefficient was 0.845 . Thus, age differences were not included in the further analyses. Next, logistic regression analyses were performed for the remaining predictors to examine if they uniquely predicted disclosure to an adult when the influence of other variables was controlled. Table 3 presents the results of logistic regression analyses. Two models are illustrated. The first model includes abuse-related predictors only. The model was significant and correctly classified $69.3 \%$ of the cases. However, analysis of the abuse-related predictors showed that only the perpetrator's age accounted for a significant amount of the variance. If the perpetrator was at least 30 years of age, it was more likely that the child had disclosed the CSA experience to an adult compared to the youngest group of perpetrators. The second model introduces children's individual characteristics as predictors. The model was significant, and the added variables significantly improved the model. The proportion of correctly classified cases was $83.6 \%$. Two of the child-related variables were significant predictors of disclosure. First, the younger the child was at the time of the experience, the more likely (s)he had disclosed to an adult. In contrast, experiencing emotional abuse by the mother decreased the 
Table 3

Logistic regression models for variables predicting disclosure of CSA to an adult.

\begin{tabular}{|c|c|c|}
\hline \multirow[t]{2}{*}{ Variable } & Model 1 & Model 2 \\
\hline & OR $(95 \% \mathrm{CI})$ & OR $(95 \% \mathrm{CI})$ \\
\hline \multicolumn{3}{|l|}{ Perpetrator's age (years) } \\
\hline $20-29$ & $0.660(0.257-1.694)$ & $5.930(0.842-41.765)$ \\
\hline 30 or more & $2.540(1.025-6.296)^{*}$ & $11.007(1.647-73.536)^{*}$ \\
\hline \multicolumn{3}{|c|}{$\begin{array}{l}\text { Force, intimidation or blackmail } \\
\text { no (ref) }\end{array}$} \\
\hline yes & $1.268(0.482-3.338)$ & $2.632(0.623-11.131)$ \\
\hline \multicolumn{3}{|l|}{$\begin{array}{l}\text { Violence } \\
\text { no (ref) }\end{array}$} \\
\hline yes & $2.274(0.732-7.062)$ & $3.182(0.595-17.002)$ \\
\hline \multicolumn{3}{|l|}{ Child's age (years) } \\
\hline $1-6$ & & $13.911(1.174-164.835) *$ \\
\hline $7-11$ & & $6.766(1.537-29.791)^{*}$ \\
\hline \multicolumn{3}{|l|}{$12-15$ (ref) } \\
\hline $\begin{array}{l}\text { Self-labeling the experienc } \\
\text { yes/not sure } \\
\text { no (ref) }\end{array}$ & & $3.624(0.979-13.407) *$ \\
\hline \multicolumn{3}{|l|}{$\begin{array}{l}\text { Quality of experience } \\
\text { positive (ref) }\end{array}$} \\
\hline insignificant & & $1.204(0.258-5.610)$ \\
\hline negative & & $2.518(0.567-11.188)$ \\
\hline \multicolumn{3}{|c|}{$\begin{array}{l}\text { Experiencing emotional abuse by mother } \\
\text { no (ref) }\end{array}$} \\
\hline yes & & $0.184(0.061-0.559)^{* * *}$ \\
\hline Nagelkerke R Square & 0.155 & 0.539 \\
\hline Hosmer \& Lemenshov test & 0.652 & 0.212 \\
\hline
\end{tabular}

${ }^{*} p \leq 0.05 * * p \ll 0.01$.

likelihood of disclosing. It should also be noted that self-labeling the experience as sexual abuse approached the limit of significance $(p=0.054)$ in predicting disclosure to an adult.

\section{Discussion}

The purpose of the present study was to explore the overall CSA disclosure rate and factors associated with disclosing, particularly to adults, in a large population-based sample of children (Finnish Child Victim Survey). In the field of CSA disclosure research, where almost all the studies have either been retrospective surveys for adults or focused on children who already have disclosed, the population-based survey for children offered several advantages. For example, the sample allowed access to children who had never disclosed to anyone, and decreased the risk of recall bias or adult reinterpretation. The population-based estimate of the CSA disclosure rate in the current study was $80 \%$, indicating that most of the children disclosed CSA to someone. However, disclosures to adults and especially to authorities were rare. The most common self-reported reason for non-disclosure in the present survey was that the experience was not judged serious enough to tell anyone about it. Logistic regression analyses showed that the age of the perpetrator and the victim at the time of abuse and having experiences of emotional abuse by the mother were the factors associated with disclosing to an adult. The key findings are discussed below in detail.

\subsection{CSA disclosure rate and recipients of the disclosure}

As expected, the overall disclosure rate of $80 \%$ was close to the rates discovered in other representative studies exploring CSA experiences with samples of adolescents or young adults (Helweg-Larsen \& Larsen, 2006; Kogan, 2004; Priebe \& Svedin, 2008; Fergusson et al., 1996; Bottoms et al., 2016). The disclosure rates in these studies were much higher than in retrospective surveys of adults reporting disclosure rates mostly between $31 \%$ and $45 \%$. As Priebe and Svedin (2008) suggested, the reason for the difference is probably adolescents' better potential to remember whether they disclosed to someone or not compared to adults. Most of the children had disclosed to a friend (48\%) and/or a parent (mother 20\%, father 12\%). However, consistent with previous research (Priebe \& Svedin, 2008; Collings et al., 2005; Lam, 2014; Kogan, 2004; Helweg-Larsen \& Larsen, 2006; Bottoms et al., 2016), the disclosure rate for adult recipients (parents and authorities) was as low as $26 \%$, and only a minority (12\%) of children reported disclosing to authorities. On the other hand, it is a comfort to know that there usually are confidants (such as friends) who have an important role in supporting and encouraging a victim to get help. Nevertheless, the number of experiences not reported to the 
authorities is worrying, even if the number of reports to the police of suspected CSA has been increasing in recent years in Finland (Fagerlund et al., 2014). The low disclosure rate to adults and authorities enables perpetrators to continue abusive acts. Also, without intervention from adults, children are unlikely to get help (Bottoms et al., 2016; Pipe et al., 2007a).

The most common self-reported reason for non-disclosure in the present study was that the sexual experience with an adult was not considered serious enough to be reported (41\%). Owing to the paucity of surveys examining children's self-reports of reasons for not disclosing (Leclerc \& Wortley, 2015; London et al., 2008; Ullman, 2007), this is an important finding to be studied further. The results may be related to children defining CSA differently compared to adults. In line with Helweg-Larsen and Larsen (2006) and Fergusson et al. (1996), the present study showed that 51\% of the children reporting sexual experiences with someone at least five years older did not label the experience as sexual abuse. In the current study, CSA was defined broadly, including also non-contact abuse (such as propositions and invitations to do something sexual). It is possible that children do not consider such acts as CSA and worth reporting to adults. In fact, the bivariate level of analysis supported this interpretation by showing that children self-labeling the experience as CSA more often disclosed to an adult compared to children who did not label the experience as CSA. Also, some of the adolescents may even find a proposition coming from an adult flattering and thus not consider it as abuse. Indeed, most of the boys $(71 \%)$ and $26 \%$ of the girls chose to describe the experience as positive. Again, it is reassuring that a large part of the nondisclosed CSA may be less serious cases, as the results suggest. On the other hand, non-disclosing less serious abuse may enable perpetrators to avoid being found out and continue offending, possibly moving on to a more severe form of abuse. It is known that perpetrators may first spend quite a long time building trust with a child and gradually moving from less serious acts to more severe abuse. Such a gradual process may be difficult to recognize as sexual or inappropriate for children (Craven, Brown, \& Gilchrist, 2007; Paine \& Hansen, 2002).

In the present study, only $14 \%$ of the respondents reported lacking the courage as a reason for non-disclosure. In contrast, studies of children undergoing an investigation process have quite commonly reported "lacking the courage" as a reason for non-disclosure. For example, children have mentioned fear of the possible consequences. The older the children, the more they were afraid of the possible negative outcomes of disclosing. In the study by Malloy et al. (2011), children referred to being afraid of negative emotions they might experience when disclosing, being physically harmed, and even being thrown into prison or dying. They often also wondered what might happen to themselves and their loved ones (Malloy et al., 2011). It is probable that children undergoing an investigation process have more serious experiences than children who have not reported their experiences to adults or authorities (see, e.g., Priebe \& Svedin, 2008; Lam, 2014). Also, children in an investigation process undoubtedly realize that disclosing to authorities has different, often more serious consequences than disclosing to friends, as the study of Malloy et al. (2011) indicated. Given that, differences between studies of children undergoing an investigation process and the present study are understandable. Also, this highlights the point that by studying only samples of children undergoing an investigation process, some of the factors related to non-disclosure at an earlier stage of the process may remain undetected.

\subsection{Factors associated with disclosing to adults}

While most of the other survey studies have examined CSA disclosure in general (disclosing to someone), the present study focused specifically on factors associated with disclosing CSA to adults (parents and/or authorities). This perspective was chosen because adults often regulate both the beginning of an investigation process and the access to getting help (Tashjian et al., 2016). The most common predictors examined in the previous studies have been victim characteristics (age and gender), offender-victim relationship, family support, and variables measuring the severity of abuse (Leclerc \& Wortley, 2015). Examining disclosure as a part of the national child victim survey also enabled consideration of some previously ignored themes, such as experiencing violence at home and how it might influence disclosing CSA to adults (Tashjian et al., 2016). Bivariate analyses showed that several variables were associated with disclosing to an adult. However, only three of them remained significant when the influence of other variables was controlled in multivariate analyses (logistic regression models). First, he perpetrator's age was the only abuse-related factor accounting for a significant amount of the variance. Where the perpetrator was at least 30 years of age, disclosing the CSA experience to an adult was more likely than where the perpetrator was less than 19 years of age. Previous research has mostly ignored the possible effect of the abuser's age on a child's willingness to disclose. However, some studies have examined the influence on disclosure of the age difference between child and abuser (Priebe \& Svedin, 2008; Kogan, 2004). Kogan (2004) found that unwanted sexual experiences with peers were more likely disclosed to a peer than to an adult. Nevertheless, Priebe and Svedin (2008) found no association between age difference and disclosure. The results suggest that further research is still needed to detect if children find sexual experiences with older adults as more inappropriate than experiences with younger adults and whether this explains why the experiences with older adults are more often reported to adults.

Previous research evidence has been mixed regarding the influence on disclosure of the age of the victim at the time of CSA (London et al., 2007; Leclerc \& Wortley, 2015). In the present study, the age of the victim at the time of the abuse was one of the individual characteristics that significantly predicted disclosure to an adult. The younger the child was at the time of the abuse, the more likely was a disclosure of the experience to an adult. This is in line with some previous studies suggesting that adolescents tend to disclose to peers, whereas younger children prefer disclosing to parents (London et al., 2007; Kogan, 2004). However, in retrospective studies, results have varied (London et al., 2007; Lippert et al., 2009), and recent surveys with young respondents have failed to find associations between age at the time of the abuse and disclosure (Bottoms et al., 2016, Lam, 2014). By contrast, studies among children specifically assessed or treated for CSA findings have fairly consistently suggested that younger children are less likely to disclose. As London et al. (2007) proposed, one of the reasons for varying disclosure rates is related to different definitions of disclosure. Therefore, the results of the present study, which focuses specifically on factors associated with disclosing CSA to adults, 
are not directly comparable to research on disclosing CSA generally or in the context of investigative interviewing.

Given that mothers were the most common adult recipients of CSA disclosure in the present study, it was not surprising that children experiencing emotional abuse by their mothers were less likely to disclose to an adult. Experiencing emotional abuse by fathers did not affect disclosing to an adult. Most of the CSA victims were girls, and for girls it is probably more natural to discuss sexual issues with their mother than with their father. Consequently, if the mother is emotionally abusive, there may be no adult to turn to regarding such a sensitive issue. This result supports the findings of the pilot study by Tashjian and colleagues (2016), who found that experiencing both emotional and physical abuse by a parental figure predicted significant delays in CSA disclosure. A possible explanation, suggested by Tashjian and colleagues (2016), among others, is that maltreated children are more likely to be insecurely attached, which is associated with difficulties in trusting parental figures to provide safety when experiencing stress (see also Shields, Ryan, \& Cicchetti, 2001; Stronach, Toth, Oshri, Manly, \& Cicchetti, 2011). Also, it is reasonable to suggest that children who expect parental figures to react unsupportively are less likely to disclose (Lawson \& Chaffin, 1992). Furthermore, it may be hypothesized that children with (emotionally) abusive parents may be less well informed about abusive behavior and how to protect themselves from it.

Gender differences in disclosing to an adult were also not detected in the present sample, in contrast to several earlier studies indicating that males are more reluctant to disclose than females (e.g., Priebe \& Svedin, 2008; for a review, see London et al., 2008). However, the finding is in line with the most recent studies on CSA disclosure (Lam, 2014; Leclerc \& Wortley, 2015; Tashjian et al., 2016) and also with some of the earlier studies (e.g., Goodman-Brown, Edelstein, Goodman, Jones, \& Gordon, 2003). Mixed evidence of the effects of gender on CSA disclosure indicates that further research is still needed before definite conclusions can be drawn.

Lastly, it should be noted that self-labeling the experience as CSA closely approached significance $(p=0.054)$ in predicting disclosure to an adult. Given the paucity of research including self-labeling as a potential variable predicting CSA disclosure and the recent findings of Bottoms et al. (2016) suggesting that self-labeling predicts disclosure generally, this is an important finding to be studied further.

\subsection{Strengths and limitations}

Since the survey was anonymous and parental consent was not required, obstacles to providing honest answers and the risk of missing respondents who had experiences of CSA were minimized. However, as always in self-reporting surveys, there was a possibility of both under- and over-reporting. In this kind of large sample, the influence of these biases has, however, been shown to be small, although it should be noted (Ellis, Hartley, \& Walsh, 2010). Nevertheless, computerized questionnaires, like the one used in the present study, have been reported to increase confidentiality and may have little reporting bias, while also increasing the accuracy of the responses (Helweg-Larsen \& Larsen, 2006). The Finnish Child Victim Survey was not designed to examine CSA disclosure alone. Therefore, only few questions related to disclosure. For example, possible delays in disclosure were not measured, and participants were not asked if anyone had asked them about CSA before. Also, the relatively small number of children who had CSA experiences $(n=256)$ probably limited the statistical power of the analyses, so that detecting significant differences was unlikely for some factors. For example, the number of observations for variables such us intra-familial CSA, child physical abuse, and ethnic background was small. It should also be noted that the relatively low prevalence of CSA (2.4\%) in the present survey may have been affected by the fact that children in special education were not included. Their risk of being abused is known to be higher than that of other children (Hershkowitz, Lamb, \& Horowitz, 2007). Nevertheless, comparing the results with earlier surveys, the prevalence of CSA has clearly decreased in Finland (Fagerlund et al., 2014).

\subsection{Conclusions and implications}

This study contributed to previous research on CSA disclosure by offering a child population-based estimate of CSA disclosure rates and children's self-reported reasons for non-disclosure. Studying disclosure as a part of the Finnish Child Victim Survey also elicited a few new perspectives on disclosure of CSA, to be considered further in future research. For example, such rarely considered factors as perpetrator's age and having experiences of emotional abuse by the mother proved to be significant in predicting disclosure of CSA to an adult. These results, taken together with the finding that many of the children did not label their experiences as sexual abuse, indicate that more age-appropriate safety education for children and adolescents is needed to encourage disclosures to adults early enough. Guidance is also needed for peers on why passing information on to a reliable adult is essential if someone tells about a CSA experience, since friends were the most common recipients of disclosure. Early disclosure is crucial, both for ending the abuse and for preventing perpetrators from moving on to new victims. A study of CSA perpetrators shows that around a third reported that their victim was able to avoid incidents of abuse by saying that he or she would tell someone about the abuse (Leclerc \& Wortley, 2015; Leclerc et al., 2011).

\section{References}

Anderson, J., Martin, J., Mullen, P., Romans, S., \& Herbison, P. (1993). Prevalence of childhood sexual abuse experiences in a community sample of women. Journal of the American Academy of Child and Adolescent Psychiatry, 32, 911-919. http://dx.doi.org/10.1097/00004583-199309000-00004.

Bottoms, B. L., Rudnicki, A. G., \& Epstein, M. A. (2007). A retrospective study of factors affecting the disclosure of childhood sexual and physical abuse. In M. E. Pipe, M. Lamb, Y. Orbach, \& A.-C. Cederborg (Eds.). Child sexual abuse: disclosure, delay, and denial (pp. 175-194). Mahwah, NJ: Erlbaum.

Bottoms, B. L., Peter-Hagene, L. C., Epstein, M. A., Wiley, T. R. A., Reynolds, C. E., \& Rudnicki, A. G. (2016). Abuse characteristics and individual differences related to disclosing childhood sexual, physical, and emotional abuse and witnessed domestic violence. Journal of Interpersonal Violence, 31, 1308-1339. http://dx.doi.org/10.1177/ 
0886260514564155 .

Browne, A., \& Finkelhor, D. (1986). Impact of child sexual abuse: a review of the research. Psychological Bulletin, 99, 66-77. http://dx.doi.org/10.1037/0033-2909.99.1.66.

Collings, S. J., Griffiths, S., \& Kumalo, M. (2005). Patterns of disclosure in child sexual abuse. South African Journal of Psychology, 35(2), 270-285. http://dx.doi.org/10.1177/ 008124630503500207.

Conte, J. R., \& Berliner, L. (1988). The impact of sexual abuse on children: empirical findings. New York, NY: Springer.

Craven, S., Brown, S., \& Gilchrist, E. (2007). Current responses to sexual grooming: implications for prevention. The Howard Journal of Crime and Justice, 46, 60-71. http://dx.doi. org/10.1111/j.1468-2311.2007.00454.x.

Ellis, L., Hartley, R. D., \& Walsh, A. (2010). Research methods in criminal justice and criminology: an interdisciplinary approach. Lanham: Rowman \& Littlefield.

Ellonen, N., \& Pösö, T. (2011a). Children's experiences of completing a computer-based violence survey: ethical implications. Children and Society, 25(6), 470-481. http://dx.doi. org/10.1111/j.1099-0860.2010.00292.x.

Ellonen, N., \& Pösö, T. (2011b). Violence experiences in care: some methodological remarks based on the Finnish Child Victim survey. Child Abuse Review, 20(3), 197-212. http:// dx.doi.org/10.1002/car.1181.

Ellonen, N., Kääriäinen, J., Salmi, V., \& Sariola, H. (2008). Lasten ja nuorten väkivaltakokemukset. [Experiences of violence among children and adolescents]. Reports of Police College of Finland, no. 71 and The National Research Institute of Legal Policy 87. Tampere: Police College of Finland.

Fagerlund, M., Peltola, M., Kääräinen, J., Ellonen, N., \& Sariola, H. (2014). Lasten ja nuorten väkivaltakokemukset. [Experiences of violence among children and adolescents]. Reports of Police College of Finland110. Tampere: Juvenes Print.

Fergusson, D. M., Lynskey, M. T., \& Horwood, L. J. (1996). Childhood sexual abuse and psychiatric disorder in young adulthood: i. Prevalence of sexual abuse and factors associated with sexual abuse. Journal of the American Academy of Child and Adolescent Psychiatry, 35, 1355-1364.

Finkelhor, D., Ormrod, R., \& Turner, H. (2007a). Polyvictimization and trauma in a national longitudinal cohort. Development and Psychopathology, 19, 149-166. http://dx.doi. org/10.1017/S0954579407070083.

Finkelhor, D., Ormrod, R., \& Turner, H. (2007b). Re-victimization patterns in a national longitudinal sample of children and youth. Child Abuse and Neglect, 31, 479-502. http:// dx.doi.org/10.1016/j.chiabu.2006.03.012.

Finkelhor, D., Ormrod, R., \& Turner, H. (2007c). Poly-victimization: a neglected component in child victimization. Child Abuse and Neglect, 31, 7-26. http://dx.doi.org/10.1016/j. chiabu.2006.06.008.

Finkelhor, D. (2007). Developmental victimology. The comprehensive study of childhood victimization. In R. Davis, A. Luigiro, \& S. Herman (Eds.). Victims of crime (pp. 9-34). Thousand Oaks, CA: Sage Publications.

Finkelhor, D. (2008). Childhood victimization. violence, crime, and abuse in the lives of young people. Oxford and New York: Oxford University Press.

Goodman-Brown, T. B., Edelstein, R. S., Goodman, G. S., Jones, D. P. H., \& Gordon, D. S. (2003). Why children tell: a model of children's disclosure of sexual abuse. Child Abuse and Neglect, 27, 525-540. http://dx.doi.org/10.1016/S0145-2134(03)00037-1.

Helweg-Larsen, K., \& Larsen, H. B. (2006). The prevalence of unwanted and unlawful sexual experiences reported by Danish adolescents: results from a national youth survey in 2002. Acta Paediatrica, 95, 1270-1276. http://dx.doi.org/10.1080/08035250600589033.

Helweg-Larsen, K. (2009). Framework for nordic youth surveys on child sexual abuse and exposure to violence outside and in the family. [Retrieved 1.6.2016 from: http://www.divaportal.org/smash/get/diva2:701419/FULLTEXT01. pdf].

Herman, J. L., \& Hirschman, L. (1981). Father-Daughter Incest. Cambridge, MA: Harvard University Press.

Hershkowitz, I., Horowitz, D., \& Lamb, M. E. (2005). Trends in children's disclosure of abuse in Israel: a national study. Child Abuse and Neglect, 29, 1203-1214. http://dx.doi.org/ 10.1016/j.chiabu.2005.04.008.

Hershkowitz, I., Lamb, M. E., \& Horowitz, D. (2007). Individual and family variables associated with disclosure and nondisclosure of child sexual abuse in Israel. In M. E. Pipe (Ed.). Child sexual abuse (pp. 63-75). .

Kogan, S. M. (2004). Disclosing unwanted sexual experiences: results from a national sample of adolescent women. Child Abuse and Neglect, 28, 147-165. http://dx.doi.org/10. 1016/j.chiabu.2003.09.014.

Lam, K. Y. I. (2014). Factors associated with adolescents' disclosure of sexual abuse experiences in Hong Kong. Journal of Child Sexual Abuse, 23, 768-791. http://dx.doi.org/10, $1080 / 10538712.2014 .950398$.

Lawson, L., \& Chaffin, M. (1992). False negatives in sexual abuse disclosure interviews: incidence and influence of caretaker's belief in abuse in cases of accidental abuse discovery by diagnosis of STD. Journal of Interpersonal Violence, 7, 532-542. http://dx.doi.org/10.1177/088626092007004008.

Leclerc, B., \& Wortley, R. (2015). Predictors of victim disclosure in child sexual abuse: additional evidence from a sample of incarcerated adult sex offenders. Child Abuse and Neglect, 43, 104-111. http://dx.doi.org/10.1016/j.chiabu.2015.03.003.

Leclerc, B., Wortley, R., \& Smallbone, S. (2011). Victim resistance in child sexual abuse: a look into the efficacy of self-protection strategies based on the offender's experience. Journal of Interpersonal Violence, 26, 1868-1883. http://dx.doi.org/10.1177/0886260510372941.

Lippert, T., Cross, T. P., Jones, L., \& Walsh, W. (2009). Telling interviewers about sexual abuse: predictors of child disclosure at forensic interviews. Child Maltreatment, 14(1), 100-113. http://dx.doi.org/10.1177/1077559508318398.

London, K., Bruck, M., Ceci, S. J., Shuman, D. W., et al. (2007). Disclosure of child sexual abuse: a review of the contemporary empirical literature. In M. E. Pipe (Ed.). Child sexual abuse (pp. 11-39).

London, K., Bruck, M., Wright, D. B., \& Ceci, S. J. (2008). Review of the contemporary literature on how children report abuse to others: findings, methodological issues, and implications for forensic interviewers. Memory, 16(1), 29-47. http://dx.doi.org/10.1080/09658210701725732.

Lyon, T. D., et al. (2007). False denials: overcoming methodological biases in abuse disclosure research. In M. E. Pipe (Ed.). Child sexual abuse (pp. 41-62). .

Malloy, L. C., Brubacher, S., \& Lamb, M. E. (2011). Expected consequences of disclosure revealed in investigative interviews with suspected victims of child sexual abuse. Applied Developmental Science, 15(1), 8-19. http://dx.doi.org/10.1080/10888691.2011.538616.

Olafson, E., \& Lederman, J. C. S. (2006). The state of the debate about children's disclosure patterns in child sexual abuse cases. Juvenile and Family Court Journal, 57, 27-40. http://dx.doi.org/10.1111/j.1755-6988.2006.tb00112.x.

Paine, M. L., \& Hansen, D. J. (2002). Factors influencing children to self-disclose sexual abuse. Clinical Psychology Review, 22, 271-295. http://dx.doi.org/10.1016/S02727358(01)00091-5.

Palmer, S. E., Brown, R. A., Rae-Grant, N. I., \& Loughlin, M. J. (1999). Responding to children's disclosure of familial abuse: what survivors tell us. Child Welfare Journal, 78, $259-282$.

Pipe, M.-E., Lamb, M. E., Orbach, Y., Sternberg, K. J., Stewart, H. L., Esplin, P. W., et al. (2007a). Factors associated with nondisclosure of suspected abuse during forensic interviews. In M. E. Pipe (Ed.). Child sexual abuse (pp. 77-96). .

Pipe, M.-E., Orbach, Y., Lamb, M., Cederborg, A.-C., et al. (2007b). Seeking resolution in the disclosure wars: an overview. In M. E. Pipe (Ed.). Child sexual abuse (pp. 3-10). .

Priebe, G., \& Svedin, C. G. (2008). Child sexual abuse is largely hidden from the adult society: an epidemiological study of adolescents' disclosures. Child Abuse and Neglect, 32, 1095-1108. http://dx.doi.org/10.1016/j.chiabu.2008.04.001.

Sariola, H., \& Uutela, A. (1992). The prevalence and context of family violence against children in Finland. Child Abuse and Neglect, 16, $823-832$.

Sariola, H., \& Uutela, A. (1994). Prevalence of child sexual abuse in Finland. Child Abuse and Neglect, 18(10), 827-835. http://dx.doi.org/10.1016/0145-2134(94)90062-0.

Sariola, H., \& Uutela, A. (1996). The prevalence and context of incest abuse in Finland. Child Abuse and Neglect, 20(9), 843-850. http://dx.doi.org/10.1016/0145-2134(96) $00072-5$.

Shields, A., Ryan, R. M., \& Cicchetti, D. (2001). Narrative representations of caregivers and emotion dysregulation as predictors of maltreated children's rejection by peers. Developmental Psychology, 37, 321-337. http://dx.doi.org/10.1037//0012-1649.37.3.321.

Straus, M. A., Hamby, S. L., Boney-McCoy, S., \& Sugarman, D. P. (1994). The revised conflict tactics scales (CTS2): development and preliminary psychometric data. Journal of Family Issues, 17, 283-316.

Stronach, E. P., Toth, S. L., Oshri, A., Manly, J. T., \& Cicchetti, D. (2011). Child maltreatment, attachment security, and internal representations of mother and mother?child relationships. Child Maltreatment, 16, 137-145. http://dx.doi.org/10.1177/1077559511398294.

Tashjian, S. M., Goldfarb, D., Goodman, G. S., Quas, J. A., \& Edelstein, R. (2016). Delay in disclosure of non-parental child sexual abuse in the context of emotional and physical maltreatment: a pilot study. Child Abuse and Neglect, 58, 149-159. http://dx.doi.org/10.1016/j.chiabu.2016.06.020.

Tolvanen, M., \& Fors, M. (2013). Lapsen houkutteleminen seksuaalisiin tarkoituksiin. Edilex35.

Ullman, S. (2007). Relationship to perpetrator, disclosure, social reactions, and PTSD symptoms in child sexual abuse survivors. Journal of Child Sexual Abuse, 16(1), 19-36. http://dx.doi.org/10.1300/J070v16n01_02.

Wyatt, G. E., \& Newcomb, M. D. (1990). Internal and external mediators of women's sexual abuse in childhood. Journal of Consulting and Clinical Psychology, 58, 758-767. 